\title{
Organic Acid Extraction of Fluoride from Antarctic Krill Euphausia superba
}

\author{
Cheng Liang Xie ${ }^{1}$, Han Soo Kim ${ }^{1}$, Kil Bo Shim², Yeon Kye Kim², Na Yeong Yoon ${ }^{2}$, Poong Ho Kim ${ }^{3}$ and \\ Ho Dong Yoon ${ }^{3 *}$ \\ ${ }^{1}$ Department of Food Science and Technology, Pusan National University, Miryang 627-706, Korea \\ ${ }^{2}$ Food \& Safety Research Division, National Fisheries Research and Development Institute, Busan 619-705, Korea \\ ${ }^{3}$ Southeast Sea Fisheries Research Institute, National Fisheries Research and Development Institute, Tongyeong 650-943, Korea
}

\begin{abstract}
The amount of fluoride removed from Antarctic krill via organic acid extraction depends on the extraction time, concentration, extraction volume, and the nature of the acid itself. The fluoride content in Euphausia superba was determined by measuring the concentration of fluoride ion in acidic extracts using an ion-selective electrode. The best results were obtained by adding $50 \mathrm{~mL}$ of 0.01 M citric acid to 0.3-0.5 g of krill and extracting for $5 \mathrm{~min}$. Under these conditions, recoveries of fluoride from frozen whole krill and krill meat were 95.6-99.5\% and 97.5-101.3\%, respectively. The dry basis fluoride contents of krill by-product, krill meat and the boiled krill were 705, 298, and 575 ppm, respectively. These levels were significantly reduced by citric acid extraction.
\end{abstract}

Key words: Fluoride Reduction, Antarctic Krill, Organic acids, Citric acid

\section{Introduction}

The Antarctic krill Euphausia superba has been the most abundant species constituting marine biomass since the 1970 s and occurs in the greatest numbers in the Antarctic Ocean. Its biomass as a single species has been estimated at approximately 60-150 million tons (Nicol and Foster, 2003). Given these plentiful resources, krill has been recognized as a potential food resource and alternative protein source for humans. Most of the commercially caught Antarctic krill are immediately processed into frozen blocks onboard the fishing vessel to be consumed primarily as recreational fishing bait. Limited amounts of krill meat are also used as fish food in aquaculture (Nicol et al., 2000).

Despite its huge biomass, Antarctic krill has not been a traditional food in the human diet because of its high fluorine content. While small amounts of fluoride in food have been shown to help prevent tooth decay, too much fluoride in the diet or long-term excessive intake of fluoride can result in macular teeth (Arthur, 1971).

Both Meganyctiphanes norvegica and E. superba contain high amounts of fluoride. M. norvegica contains 1,300-2,400 $\mathrm{mg} / \mathrm{kg}$ dry matter (Soevik and Braekkan, 1979), while E. superba contains approximately $1,137 \mathrm{mg} \mathrm{F}^{-} / \mathrm{kg}$ dry weight (Malde et al., 2001). Kumagai (1984) measured the fluoride content of E. superba and tiger prawn Penaeus japonica at 490 and $1.6 \mu \mathrm{g} / \mathrm{g}$, respectively, based on wet weight. Fluorine is a component of the krill exoskeleton and the natural amount of fluorine in whole-body krill has been reported as 1,009-7,806 ppm. In krill meat (KM), the amount of fluorine ranges from 4.5 to 570 ppm dry weight (Zhang et al., 1993). The exoskeleton and cephalothorax can contain approximately 200 ppm dry weight (Szewielow, 1981). The relatively high fluoride content of krill makes it questionably suitable as a
Open Access http://dx.doi.org/10.5657/FAS.2012.0203

This is an Open Access article distributed under the terms of the Creative Commons Attribution Non-Commercial License (http://creativecommons. org/licenses/by-nc/3.0/) which permits unrestricted non-commercial use, distribution, and reproduction in any medium, provided the original work is properly cited. pISSN: 2234-1749 eISSN: 2234-1757
Received 17 July 2012; Revised 17 August 2012;

Accepted 22 August 2012

*Corresponding Author

E-mail: hdy8623@nfrdi.go.kr 
large-scale protein source in human food and animal feed. However, Antarctic krill have attracted some attention as a potential, indirect protein resource for humans (Soevik and Braekkan, 1979).

Several reports describing the removal and/or quantitation of fluoride in krill and other foods have been published. A simple, rapid, and reliable analytical procedure for determining fluoride levels in biological samples employs alkali fusion and fluoride ion-selective electrodes (Kumagai, 1984; Malde et al., 2001). Kim et al. (1990) studied the migration of fluoride from chitinous components into the muscle of frozen krill (FK) during thawing and reviewed an electrocondensation method as a means of reducing the fluoride content of Antarctic krill. Fluorine removal during the production of krill paste and krill protein concentrates was studied by Filho (1993). The amount of soluble protein in krill muscle depends on $\mathrm{pH}$, ion species, and the ionic strength of the extracting solutions (Park et al., 1988).

This report details the removal of fluoride from Antarctic krill using an optimized organic acid extraction. Such a pretreatment would allow krill to be used as a protein substitute in human food and aquacultural fish meal.

\section{Materials and Methods}

\section{Sample preparation}

Antarctic krill Euphausia superba were caught in March 2010 by Dong Won Fisheries Co., Ltd. FK, KM, krill by-product $(\mathrm{KB})$, and boiled krill (BK) were produced onboard the fishing vessel immediately after the catch and were frozen to $-35^{\circ} \mathrm{C}$. Samples were lyophilized or dried and stored at $-35^{\circ} \mathrm{C}$ until analysis.

\section{Measuring fluoride levels by alkali fusion}

The fluoride content of the krill was determined using a method developed by Malde et al. (2001). Approximately 0.25-0.50 g samples were weighed directly into nickel crucibles. The samples were covered with $2.5-5.0 \mathrm{~mL}$ of $8 \mathrm{M}$ sodium hydroxide, depending on the amount of sample. The crucibles were put on a hot plate and evaporated to dryness before being put into a muffle furnace for combustion. The muffle furnace temperature was set at $200^{\circ} \mathrm{C}$ for approximately $16 \mathrm{~h}$ and then raised to $525^{\circ} \mathrm{C}$ and held for another $3 \mathrm{~h}$. The crucibles were cooled, $10-15 \mathrm{~mL}$ of distilled water was added, and the crucibles were placed on a hotplate to aid the dissolution of the fusion cake. After approximately $2 \mathrm{~h}$, the sample solutions were transferred to $50 \mathrm{~mL}$ plastic tubes and capped.

The sample solutions were then neutralized with concentrated hydrochloric acid, added dropwise until the $\mathrm{pH}$ de- creased from $12.0-13.0$ to $8.0-8.5$. The $\mathrm{pH}$ was then reduced to 7.2-7.5 by adding dilute hydrochloric acid with a titrator. The sample solution was transferred to a $50-\mathrm{mL}$ plastic volumetric flask and stored until analysis. Aliquots of $10 \mathrm{~mL}$ were removed from the volumetric flask and $1 \mathrm{~mL}$ of TISAB III was added to each aliquot, bringing the $\mathrm{pH}$ to 5.2-5.4. Reagent blanks were used as negative controls and standard solutions were prepared with fluoride concentrations of $0.100,1.00$, and $10.0 \mathrm{mg} \mathrm{F}^{-} / \mathrm{L}$. The standard and sample solutions were analyzed with a fluoride ion-selective electrode (9609BNWP and 960900 fluoride combination electrode, Orion Dual Star, pH/ISE Benchtop; Thermo Scientific, Waltham, MA, USA). The electrode was rinsed and blotted dry before each measurement.

\section{Measuring fluoride levels by organic acid extraction}

Aliquots of 0.5-2.0 $\mathrm{g}$ of lyophilized FK were weighed into plastic beakers. To each aliquot was added 50-200 mL of 0.01$0.1 \mathrm{M}$ citric acid and the mixtures were stirred with an agitator for 5-30 min. The mixtures were then centrifuged, filtered, and adjusted to $\mathrm{pH} 7.2-7.5$ with a $\mathrm{NaOH}$ solution. Five milliliters of each filtrate was placed into a $10-\mathrm{mL}$ volumetric flask. One milliliter of a TISAB III solution was added and the fluoride concentration was measured using the fluoride ion-selective electrode described above.

\section{Percent recovery using fluoride standard solutions}

To a beaker were added $0.5 \mathrm{~g}$ samples of FK and KM, an aliquot of fluoride standard solution, and $50 \mathrm{~mL}$ of $0.01 \mathrm{M}$ citric acid. The mixture was then stirred for 5 min and filtered. Tenmilliliter aliquots of filtrate were removed from the beaker, adjusted to $\mathrm{pH}$ to 7.2-7.5 with $0.1 \mathrm{M} \mathrm{NaOH}$, and transferred to a $10-\mathrm{mL}$ volumetric flask. One milliliter TISAB III was added the flask and the fluoride concentration was measured with an ion-selective electrode as above. Percent recovery test was calculated as follows:

Percent recovery of added fluoride $=(\mathrm{F} 2-\mathrm{F} 1) / \mathrm{F} 3 \times 100 \%$

F1: Fluoride content of the sample

F2: Fluoride content of the sample after adding the fluoride standard

F3: Amount of added fluoride

\section{Statistical analyses}

All of the measurements performed on powders of $\mathrm{KB}$, $\mathrm{KM}$, and $\mathrm{BK}$ were done in triplicate. The results of each measurement are expressed as the mean $\pm \mathrm{SD}$. Analysis of variance (ANOVA) and Duncan's multiple range tests were used to determine statistical significance at $P<0.05$. 


\section{Results and Discussion}

\section{Type and concentration of organic acids}

Fig. 1 shows the changes in fluoride concentration of solutions extracted from lyophilized FK samples as a function of acid concentration. Citric, acetic, tartaric, lactic, oxalic, succinic, malic, and fumaric acids were evaluated for their ability to remove fluoride from lyophilized FK.

The degree of fluoride removal increased significantly with increasing organic acid concentration from 0.001 to $0.1 \mathrm{M}$. Citric acid was particularly effective at extracting fluorine from lyophilized FK, although malic, tartaric, and lactic acids were also effective at a concentration of $1.0 \mathrm{M}$. Above $0.1 \mathrm{M}$ citric acid, however, the amount of extracted fluoride remained the same. Most of the organic acids exhibited their highest extraction efficiency at concentrations between 0.1 and $0.3 \mathrm{M}$. Succinic, lactic, oxalic, and fumaric acids exhibited steadily increasing efficiencies from 0.1 to $1.0 \mathrm{M}$, but yielded unstable extraction efficiencies at higher concentrations. Among the eight organic acids, citric acid was the most effective in extracting fluoride from lyophilized FK.

\section{Extraction time and temperature}

The amount of fluoride extracted from FK increased with increasing extraction time until reaching a plateau at $300 \mathrm{~s}$ (Fig. 2).

Therefore, a 5-min extraction time was deemed sufficient with $0.1 \mathrm{M}$ citric acid solution. Kumagai (1984) reported that the extraction of fluoride from krill using $0.05 \mathrm{~N} \mathrm{HClO}_{4}$ at room temperature was constant over $30 \mathrm{~min}$. The effects of temperature on fluoride extraction with citric acid were also evaluated from $20^{\circ} \mathrm{C}$ to $90^{\circ} \mathrm{C}$. No significant difference $(P>$ $0.05)$ was observed in extraction efficiency as a function of temperature (Table 1).

\section{Concentration of citric acid in the extraction solution}

Lyophilized FK was treated with 0.001-0.10 M citric acid and the fluoride concentrations of the resulting extracts were measured (Fig. 3). With $1.0 \mathrm{~g}$ of FK and $50 \mathrm{~mL}$ of citric acid solution, fluoride levels in the extracted solutions increased with increasing citric acid concentration from $0.001 \mathrm{M}$ until reaching a plateau at $0.01 \mathrm{M}$. Thus, the optimum concentration of citric acid for fluoride extraction was $0.01 \mathrm{M}$.

\section{Volume of the extraction solution}

Fig. 4 shows the fluoride removed from lyophilized FK as a function of citric acid extraction solution volume from 15 to $150 \mathrm{~mL}$. The extraction was performed for $5 \mathrm{~min}$ on a $1 \mathrm{~g}$ sample. Extracted fluoride levels increased with the volume of the extraction solution from 15 to $50 \mathrm{~mL}$. No further increase

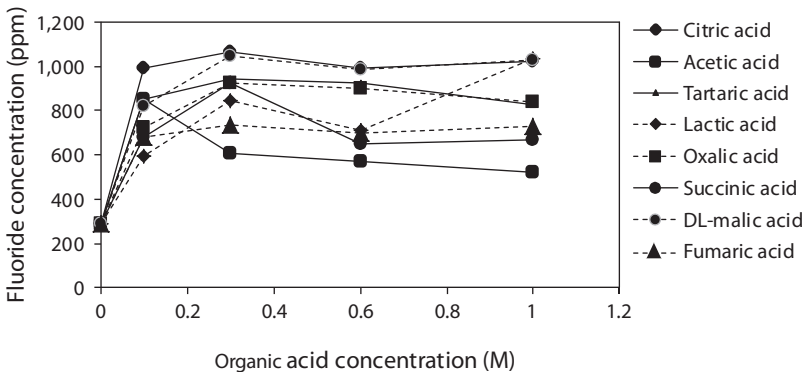

Fig. 1. Effect of various kinds and concentration of organic acids on extraction of fluoride in krill.

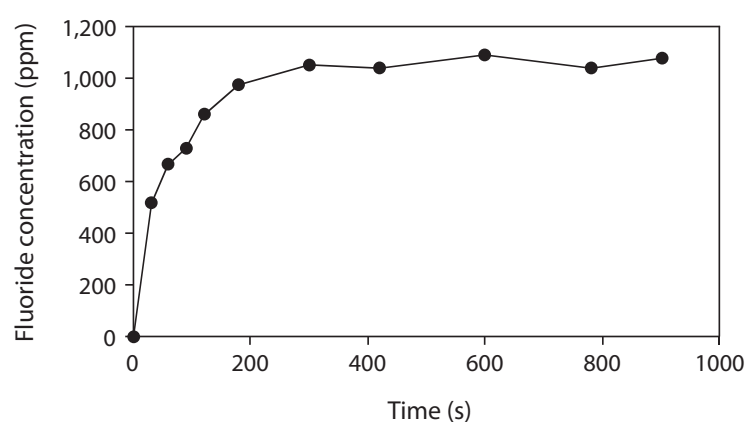

Fig. 2. Effect of time on the extraction of fluoride in krill.

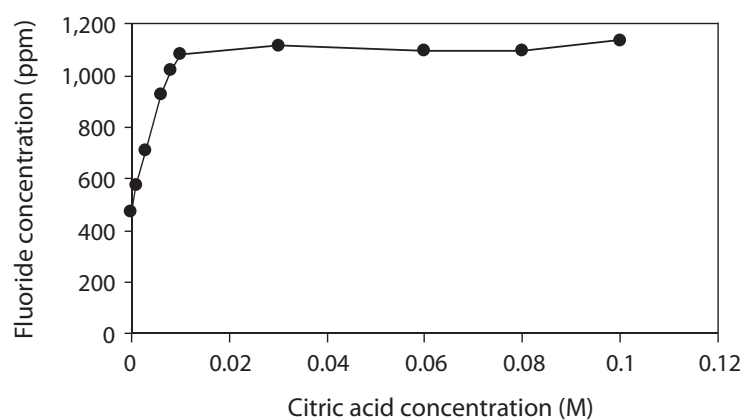

Fig. 3. Effect of citric acid volume on the extraction of fluoride in krill.

Table 1. Effect of temperature of citric acid solution on fluoride contents in krill Euphausia superba

\begin{tabular}{ccc}
\hline $\begin{array}{c}\text { Temperature } \\
\left({ }^{\circ} \mathbf{C}\right)\end{array}$ & $\begin{array}{c}\text { Mean value of } \mathbf{F} \\
(\mathbf{p p m})\end{array}$ & $\begin{array}{c}\text { Standard } \\
\text { deviation }\end{array}$ \\
\hline 20 & $1,238.0^{\mathrm{a}}$ & $55.5^{\mathrm{a}}$ \\
30 & $1,216.9^{\mathrm{a}}$ & $70.9^{\mathrm{a}}$ \\
40 & $1,178.5^{\mathrm{a}}$ & $127.1^{\mathrm{a}}$ \\
50 & $1,211.8^{\mathrm{a}}$ & $103.8^{\mathrm{a}}$ \\
60 & $1,268.4^{\mathrm{a}}$ & $128.1^{\mathrm{a}}$ \\
70 & $1,219.2^{\mathrm{a}}$ & $101.1^{\mathrm{a}}$ \\
80 & $1,239.6^{\mathrm{a}}$ & $153.7^{\mathrm{a}}$ \\
90 & $1,273.7^{\mathrm{a}}$ & $45.6^{\mathrm{a}}$ \\
\hline
\end{tabular}

Value (mean \pm SD of three replications) in each temperature with same superscripts are not significant different $(P>0.05)$. 


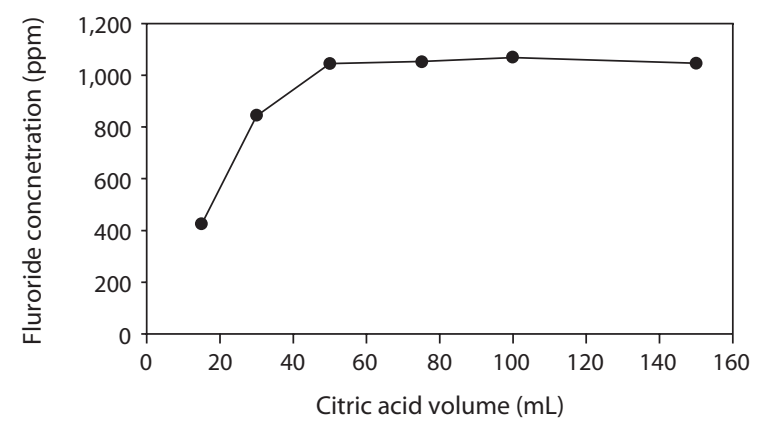

Fig. 4. Effect of citric acid volume on the extraction of fluoride in krill.

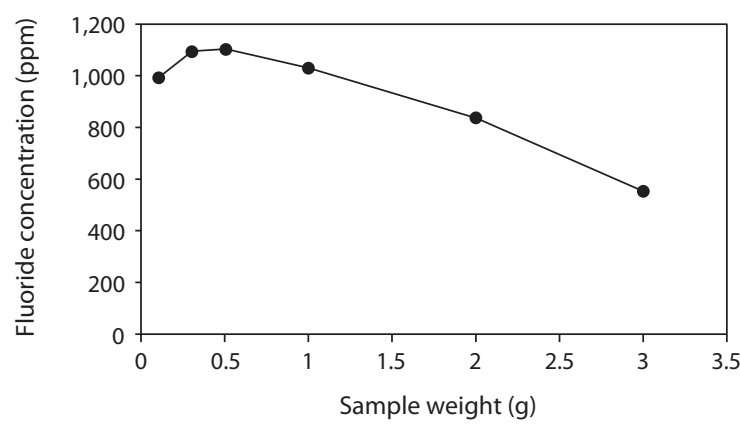

Fig. 5. Effect of sample weight on the extraction of fluoride in krill.

Table 2. Recoveries of fluoride from frozen krill and krill meat (dry basis)

\begin{tabular}{ccccc}
\hline Sample & Fluoride content $(\boldsymbol{\mu g})$ & Fluoride added $(\boldsymbol{\mu g})$ & Fluoride found $(\boldsymbol{\mu g})$ & Recovery $(\boldsymbol{\%})$ \\
\hline FK & $537.65 \pm 1.22$ & 300 & $824.50 \pm 8.19$ & $95.6 \pm 2.5$ \\
& $536.58 \pm 0.49$ & 150 & $685.83 \pm 8.36$ & $99.5 \pm 5.7$ \\
KM & $149.29 \pm 0.18$ & 300 & $441.71 \pm 5.45$ & $97.5 \pm 1.8$ \\
& $149.74 \pm 0.68$ & 150 & $301.74 \pm 3.97$ & $101.3 \pm 2.9$ \\
\hline
\end{tabular}

FK, frozen krill; KM, krill meat.

Table 3. Comparisons of fluoride contents obtained by alkali fusion method and by citric acid extraction (dry basis)

\begin{tabular}{lcc}
\hline Sample & $\begin{array}{c}\text { Alkali fusion method } \\
(\mathbf{p p m})\end{array}$ & $\begin{array}{c}\text { Citric acid extraction } \\
(\mathbf{p p m})\end{array}$ \\
\hline KB & $691.5 \pm 38.5^{\mathrm{a}}$ & $705.2 \pm 20.4^{\mathrm{a}}$ \\
$\mathrm{KM}$ & $296.6 \pm 23.3^{\mathrm{a}}$ & $297.8 \pm 12.8^{\mathrm{a}}$ \\
$\mathrm{BK}$ & $546.6 \pm 16.2^{\mathrm{a}}$ & $575.1 \pm 41.8^{\mathrm{a}}$ \\
Frozen krill & - & $1,041.9 \pm 27.7^{\mathrm{a}}$ \\
Krill meal & - & $1,942.6 \pm 48.1^{\mathrm{a}}$ \\
\hline
\end{tabular}

Value (mean \pm SD of three replications) in each row with same superscripts are not significant different $(P>0.05)$.

$\mathrm{KB}$, krill by-product; KM, krill meat; $\mathrm{BK}$, boiled krill.

was observed at volumes greater than $50 \mathrm{~mL}$. Thus, the optimum volume of $0.01 \mathrm{M}$ citric acid solution for the extraction of fluoride from lyophilized FK was $50 \mathrm{~mL}$.

\section{Amount of sample}

To optimize sample size for fluoride extraction, fluoride concentrations were measured after 5-min extractions (with $50 \mathrm{~mL}$ of $0.01 \mathrm{M}$ citric acid) of 0.1-3.0 g lyophilized FK (Fig. 5 ). The amount of fluoride eluted increased from 0.1 to 0.5 $\mathrm{g}$ and then decreased with increasing sample sizes above 0.5 g (Fig. 5). Therefore, with extractions performed using the aforementioned optimized parameters $0.3-0.5 \mathrm{~g}$ of sample were ideal.

\section{Percent recovery of fluoride from krill by stan- dard additions}

The percent recovery of fluoride (as determined by standard additions) from lyophilized FK and KM are given in Table 2. Recoveries of spiked fluoride (150 and $300 \mu \mathrm{g}$ fluoride added to each sample) were $95.6 \pm 4.7 \%$ and $99.5 \pm 5.7 \%$ for lyophilized FK and $97.5 \pm 1.8 \%$ and $101.3 \pm 2.9 \%$ for lyophilized KM, respectively. Thus, recoveries were acceptable with a range of 95.6-101.3\%. Kumagai (1984) reported recoveries of fluoride ranging from $93.3 \%$ to $96.9 \%$ for 18 samples of fluoride extract using an ion-selective electrode. Their extraction procedure consisted of shaking 1-2 $\mathrm{g}$ of sample in $100 \mathrm{~mL}$ of $0.05 \mathrm{~N} \mathrm{HClO}_{4}$ for 45-60 min. Malde et al. (2001) reported fluoride recoveries from $80 \%$ and $110 \%$. These data agree with the values obtained in the current study, although the present study used a lower ionic strength of citric acid and a shorter extraction time. No significant differences were observed in percent recovery between the samples and spiked fluoride solutions used in the present study.

\section{Comparison of fluoride content as determined by alkali fusion methods and citric acid extraction}

The fluoride contents of lyophilized FK, KM, and BK determined by alkali fusion methods and by citric acid extraction are given in Table 3. Levels of $691.46 \pm 38.48,296.58$ \pm 23.30 , and $546.61 \pm 16.23$ ppm (dry matter), respectively, were obtained using alkali fusion methods. Levels of 705.23 
$\pm 20.38,297.78 \pm 12.77$, and $575.11 \pm 41.76 \mathrm{ppm}$ (dry matter) were obtained using citric acid extraction for FK, KM, and $\mathrm{BK}$, respectively. The two methods yielded statistically identical results $(P>0.05)$, thereby indicating that the fluoride in krill can be extracted using citric acid.

Fluorine levels in frozen krill and krill meal were 1041.9 \pm 27.7 and $1942.6 \pm 48.1 \mathrm{ppm}$ (dry matter), respectively. These high fluorine levels have been associated with the ability of krill to live in below-freezing waters (Soevik and Braekkan, 1979). For E. superba, whole-body fluorine levels were 1,137 $\mathrm{mg} \mathrm{F}^{-} / \mathrm{kg}$ dry weight (Malde et al., 2001) and $490 \mu \mathrm{g} / \mathrm{g}$ wet weight (Kumagai, 1984) have been reported. Additional studies have reported levels of 215 ppm in raw muscle (Park et al., 1988), 1,920.4 ppm in whole body, $99 \mathrm{mg} \mathrm{F}^{-} / \mathrm{kg}$ dry weight in muscle (Kim et al., 1990), 2,400 ppm in whole body, and 570 $\mathrm{mg} \mathrm{F}^{-} / \mathrm{kg}$ dry matter in muscle (Soevik and Braekkan, 1979).

The amount of soluble protein in krill muscle depends on the $\mathrm{pH}$. The amount of extracted fluorine depends on the ionic strength of, and the types of ionic species in, the extracting solution. The amount of fluoride extracted from krill decreased from 64.5 to $8 \mathrm{ppm}$ when extracting with an ionic strength of $0.05 \mathrm{M} \mathrm{NaCl}$ at $\mathrm{pH} 11$ (Park et al., 1988). An electrocondensation method using an aluminum electrode was also developed as a means of removing excess fluoride from Antarctic krill. For the chitinous components of Antarctic krill, 30-70\% of the total fluoride could be removed after $120 \mathrm{~min}$ of electrocondensation (Kim et al., 1990).

The results of the current study show that citric acid extraction was just as effective as the methods of Park et al. (1988) and Kim et al. (1990) for reducing the amount of fluoride in prepared krill samples. Citric acid is a common food additive that is considered safe for consumption throughout the food industry. In this study, the most effective extraction of fluoride from krill was achieved using $50 \mathrm{~mL}$ of $0.01 \mathrm{M}$ citric acid for 5 min on $0.3-0.5 \mathrm{~g}$ samples.

Although present legislation in the Republic of Korea has set the maximum fluorine level for drinking water at $2.0 \mathrm{mg} / \mathrm{L}$, $100 \mu \mathrm{g} / \mathrm{g}$ for fish protein concentrates is permitted by the US Food and Drug Administration (US FDA), and up to 2.5 and $4.0 \mathrm{mg}$ of fluorine per day are considered safe dietary intakes for children and adults, respectively (National Academy of Sciences, 1989; Brown, 1990). A current need exists to determine acceptable limits of fluoride in various foods and to define maximum allowable levels of dietary fluoride prior to using krill biomass as a nutritional supplement for humans.

\section{Acknowledgments}

This research was a portion of the research project, " Development of technologies for food resources in future with high nutritional value from Antarctic krill (Project number 20103064)," funded by the Ministry for Food, Agriculture, Forestry and Fisheries in the Republic of Korea

\section{References}

Arthur BD. 1971. Biologic Effects of Atmospheric Pollutants, Fluoride. National Academy of Science, Washington, DC, US.

Brown ML. 1990. Present Knowledge in Nutrition. International Life Sciences, Institute Nutrition Foundation, Washington, DC, US, pp. 274-278

Filho TA. 1993. Fluorine removal during production of krill paste and krill protein concentrates. Acta Aliment 22, 269-281.

Kim KH, Kim DM, Kim YH and Yoon HH. 1990. Fluoride migration of frozen antarctic krill according to thawing methods. Korean J Food Sci Technol 22, 168-171.

Kumagai M. 1984. Simple and rapid method for determination of fluoride in Antarctic krill. Bull Jpn Soc Sci Fish 50, 1877-1881.

Malde MK, Bjorvatn K and Julshamn K. 2001. Determination of fluoride in food by the use of alkali fusion and fluoride ion-selective electrode. Food Chem 73, 373-379.

National Academy of Sciences. 1989. Recommended Dietary Allowances. 10th ed. National Academy Press, Washington, DC, US, p. 284.

Nicol S and Foster J. 2003. Recent trends in the fishery for Antarctic krill. Aquat Living Resour 16, 42-45.

Nicol S, Forster I and Spence J. 2000. Products derived from krill. In: Krill: Biology, Ecology and Fisheries. Everson I, ed. Blackwell Science Ltd., Oxford, GB, pp. 265-268.

Park HJ, Ham KS, Kim DM and Kim KH. 1988. Decrease of fluoride content of antarctic krill. Korean J Food Sci Technol 20, 19-22.

Soevik T and Braekkan OR. 1979. Fluoride in Antarctic krill (Euphausia superba) and Atlantic krill (Meganyctiphanes norvegica). J Fish Res Board Can 36, 1414-1416.

Szewielow A. 1981. Fluoride in krill (Euphausia superba Dana). Meeresforschung 28, 244-246.

Zhang H, Pan J, Cheng X and Zhu B. 1993. Biogeochemistry research of fluoride in Antarctic ocean. I. The study of fluoride anomaly in Antarctic krill. Antarct Res 4, 55-61. 